\title{
Aprendizado de TI: Um modelo para melhorar o aprendizado de TI nas organizações
}

\author{
Gabriel Ulian Briganó, Rodolfo Miranda de Barros \\ Departamento de Computação - Universidade Estadual de Londrina UEL \\ Cx. Postal 6001 - 86051-980 - Londrina - PR - Brazil \\ gabrielbriganodgmail.com, rodolfo@uel.br
}

\begin{abstract}
With the growth of information and the need to manage them, organizations have invested in digital devices to best meet their needs. These digital solutions are known as Information Technology (IT), just like other resources, it should also be controlled and managed to be aligned with the organization goals, this is called IT governance (ITG). This article offers a study aimed at developing a methodology for developing knowledge in ITG. This methodology consists in a set of tasks that enable organizations to know and find a way to mature the IT.
\end{abstract}

Resumo: Em meio ao crescimento de informações e da necessidade de gerenciálas, as organizações têm investido em mecanismos digitais para melhor atender a suas necessidades. Estas soluções digitais são conhecidas como Tecnologia da Informação (TI) e, assim como outros recursos também devem ser controlados e gerenciados para que sempre estejam alinhados com os objetivos da organização que os detém, a isto se dá o nome de Governança de TI (GTI). Baseando-se nestes fatos, este artigo oferece um estudo voltado para a criação de uma metodologia de desenvolvimento de conhecimento em GTI. Esta metodologia consiste em um conjunto de tarefas que possibilitam as organizações a se conhecerem e a descobrirem um caminho para amadurecer a TI.

\section{Introdução}

Com o crescimento do volume de informações, as organizações têm recorrido a mecanismos automatizados para melhor gerenciá-las e tirar delas o melhor proveito para os seus objetivos estratégicos, a isso se dá o nome de Tecnologia da Informação (TI) (Albertin, 2008).

Com a necessidade crescente de informações precisas e a concorrência de mercado cada vez mais forte, as organizações estão mudando o modo de enxergar a TI. Até metade da década passada, a TI era para a maioria das organizações apenas fonte de custos e gastos, atuando apenas como uma área que suporta o negócio da organização. Com o desenvolvimento do mercado e das soluções, a TI agora é vista como um ativo estratégico dentro da organização, ou seja, é possível alinha-la com os objetivos estratégicos da organização para que esta permaneça ativa e competitiva no mercado (Albertin, 2008).

Esta mudança de enfoque sobre a TI fez surgir interesse em estudos sobre ela e sobre a sua utilidade para as organizações. Prova disso é o crescente número de publicações, congressos, eventos e cursos focados unicamente para a gestão de TI. Diante deste crescimento, notou-se que um bom desenvolvimento da tecnologia da informação 
dentro das organizações necessita de mecanismos para melhor governá-la. Dessa forma, um conceito já conhecido na disciplina de administração de empresas, a governança corporativa, passou a ser aplicada na TI, dando origem a governança de TI (Lunardi, 2010).

Inicialmente, este fato impactava principalmente empresas globais, mas com o passar dos anos passou a influenciar empresas menores, de caráter regional. Assim as micro e pequenas empresas também se despertaram para o uso e desenvolvimento de TI como um ativo estratégico.

Iniciado em 2008 com o projeto Gerenciamento de Serviços de TI (GERTI), um grupo de pesquisadores e profissionais da área de TI da região norte do Paraná, tem buscado realizar a integração entre a Universidade Estadual de Londrina e o mercado corporativo, em busca de desenvolver soluções e meios para que as pequenas e médias empresas da região desenvolvam sua TI de modo consciente e façam dela um ativo estratégico [Briganó e Barros 2010].

A partir destas pesquisas notou-se a necessidade de se criar uma metodologia que apoie as micro e pequenas empresas na obtenção de um melhor aproveitamento da TI. Então iniciou-se o desenvolvimento de uma Metodologia para o Desenvolvimento de Conhecimento em Governança de TI (MDCGTI). Os conceitos e técnicas utilizados no desenvolvimento desta metodologia estão descritos na sessão 2 , seguido da explicação da metodologia e de seu funcionamento, na sessão 4 são explicados os resultados e por fim a conclusão na sessão 5 ..

\section{Referencial Teórico}

Nesta sessão são descritos alguns assuntos importantes para o entendimento da metodologia proposta neste artigo.

\subsection{Tecnologia da Informação.}

A Tecnologia da Informação (TI) consiste em sistemas de informação, ferramentas, recursos tecnológicos, hardwares, software entre outros ativos que possam ser utilizados para se obter um maior controle e organização das informações organizacionais, ainda é um dos componentes mais importantes do ambiente empresarial atual, e as organizações brasileiras têm utilizado ampla e intensamente essa tecnologia, tanto em nível estratégico como operacional (Albertin, 2008).

"As empresas utilizam a Tecnologia da Informação cada vez com mais intensidade e amplitude, não apenas bits, bytes e demais jargões, mas como uma poderosa ferramenta empresarial, que altera as bases da competitividade e as estratégias empresariais. As organizações passaram a realizar seus planejamentos e a criar suas estratégias voltadas para o futuro, tendo como uma de suas principais bases a TI, devido a seus impactos sociais e empresariais" [Albertin, 2004]. Que dizer que o cenário empresarial tem se alterado de modo que suas bases passaram a ser lançadas sobre a TI.

Este fato possibilita que as organizações obtenham um maior controle sobre as informações de seu negócio e sejam capazes de tomarem decisões mais assertivas no que diz respeito a seus caminhos. Dessa forma, a TI passa a assumir um papel de protagonista no planejamento e direcionamento das empresas, ainda que as decisões sejam tomadas pelos gestores, acionistas e executivos das organizações, ela oferece a eles subsídios para uma boa e consistente tomada de decisão. 


\subsection{Governança Corporativa}

A governança corporativa lida com toda a organização, principalmente com o processo de tomada de decisão que é praticado pelos executivos, conselheiros e acionistas. O termo Governança Corporativa (GC) pode ser definido como o conjunto de mecanismos que visam fazer com que as decisões corporativas sejam sempre tomadas com a finalidade de maximizar a perspectiva de geração de valor de longo prazo para o negócio. Ela ainda tem a finalidade de resolver problemas existentes nas organizações, como conflitos de interesses, limitações técnicas individuais, e vieses cognitivos, que consiste na tendência de indivíduos tomarem decisões erradas em função de suas características cognitivas [Silveira, 2010].

\subsection{Governança de TI}

Segundo Weill e Ross (2010), "governança de TI é o modelo como as decisões são tomadas e responsabilidades direcionadas para encorajar um comportamento desejável no uso de TI", aonde o comportamento desejável se refere a aquele que é alinhado com os objetivos e metas e coerente com a cultura da organização.

A Governança de TI consiste, em suma, em políticas, fluxos e regras que visam alinhar a TI com os objetivos de negócio da organização, permitindo-se organizar e planejar como se obter as informações necessárias à empresa. Este planejamento deve oferecer mecanismos de controle e recuperação de informações condizentes com as necessidades da empresa ao qual está incorporado.

Ainda, segundo o ITGI (2010) a governança de TI tem alguns propósitos, que seguem abaixo:

- Alinhar a TI com a organização e alcançar os benefícios esperados.

- Utilizar a TI para permitir que a organização explore melhor as oportunidades e maximize os benefícios.

- Utilizar os recursos de TI com responsabilidade.

- Gerenciar os riscos relacionados a TI apropriadamente.

A área de governança de TI tem sido estudada por muitos pesquisadores e institutos. Um exemplo disso é o fato de o Center for Information System Research (CISR) do Massachusetts Institute of Technology (MIT), ter realizado 9 anos de pesquisas intensas, com diversas empresas e diretores de TI do mundo todo. Segundo suas pesquisas, o MIT, afirma que a TI deve ser transformada em um ativo estratégico pelas empresas, e para tornar isso viável é necessário a implantação de uma plataforma digitalizada [Weill e Ross 2010].

Existem no mercado alguns modelos para se implantar a governança de TI, os principais são: CobIT (Control Objectives for Information and Related Technology), que oferece guias para se obter um melhor controle sobre a TI da organização (Fagundes, 2009) e o ITIL (Information Technology Infrastructure Library), focado na operação dos serviços de TI (ITSMF, 2007). Ainda existem alguns modelos que suportam e/ou auxiliam a governança de TI, estes modelos são: o PMBOK (Project Management Body of Knowledge), publicado pelo PMI, que oferece um conjunto de processos para guiar a gestão de projetos (PMI, 2010). O CMMI (Capability Maturity Model Integration for Software) que oferece diretrizes para o desenvolvimento de software, O MPS.Br (Melhoria de Processo de Software - Brasil) que oferece diretrizes para o desenvolvimento de 
software adaptadas ao mercado brasileiro, e o BSC (Balanced Scorecard) que é uma metodologia de gestão baseada em indicadores financeiros e não financeiros.

\subsection{Governança Corporativa $x$ Governança de TI}

O ITGI (2010) deixa claro que a governança de TI é parte integrante da Governança Corporativa e consiste na liderança de estruturas organizacionais e processos para garantir que a tecnologia da informação da organização seja capaz de expandir e prolongar as estratégias e objetivos da organização.

Dessa forma a GTI está contida dentro da GC, de forma que a GC engloba demais áreas da empresa, tais como: RH, financeiro e jurídico. A GTI se volta apenas para a área de TI e seus ativos, preocupando-se sempre em realizar operações para alcançar, manter e/ou aperfeiçoar o alinhamento da TI com o negócio. Isso faz com que a GTI se reporte para a GC, uma vez que a GC tem uma visão geral de toda a empresa e pode tomar decisões baseadas em dados reportados pela GTI, na figura 1 a GTI está destacada na cor cinza.

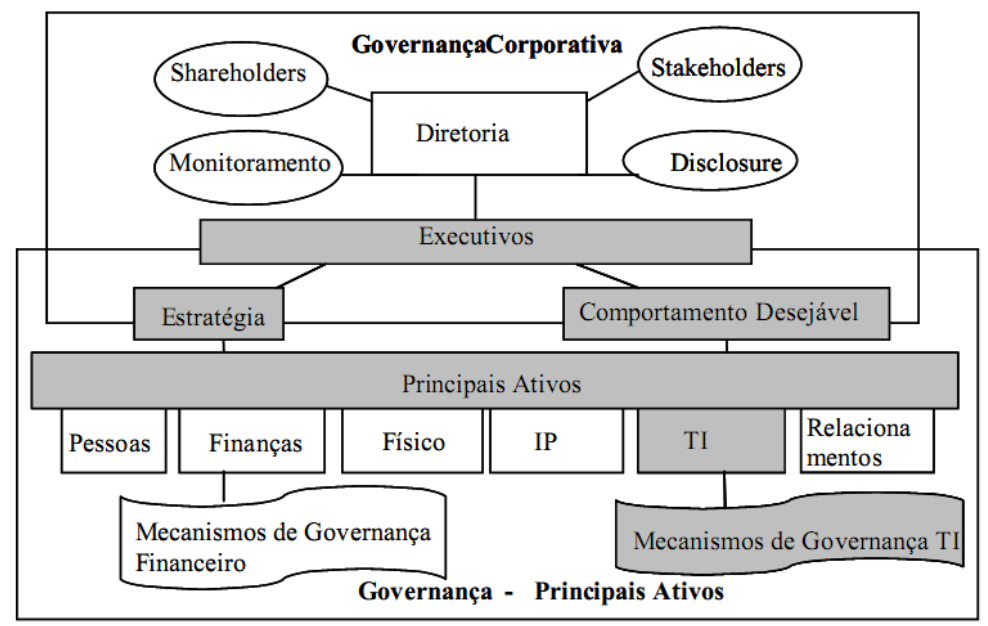

Figura 1 - Governança de TI e Governança Corporativa [Weill e Ross 2006].

\subsection{Gerenciamento de TI}

Enquanto a governança da tecnologia da informação lida com estratégia e alinhamento da TI ao negócio, o gerenciamento de TI lida com a operação dos serviços e preocupa-se em manter todos os serviços operacionais segundo as exigências de cada um. Dessa forma, o gerenciamento de TI está focado em mantê-la funcionando corretamente enquanto a governança preocupa-se com o desenvolvimento da TI e o alinhamento estratégico com o negócio [Gremberger 2004 apud Gama e Martinelo 2006]. 


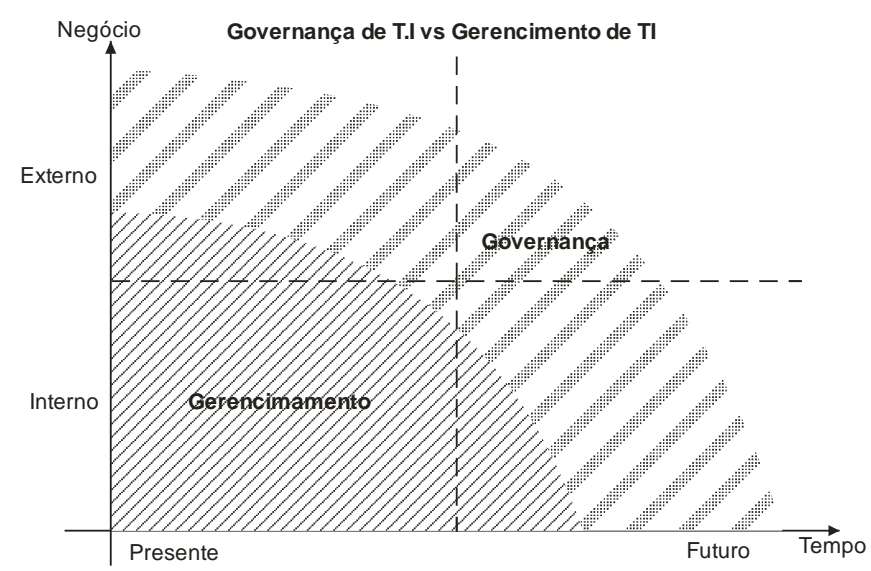

Figura 2 - Governança de TI e Gerenciamento de TI.

Conforme a figura 2 pode-se perceber que a Governança está focada para aspectos futuros e externos da organização, tais como objetivos de negócios e oportunidades. Enquanto o gerenciamento está mais focado em garantir o funcionamento interno dos serviços de modo imediato, garantindo a operacionalidade da organização.

\subsection{Conhecimento em TI}

"Conhecimento em TI é uma característica de empresas e de seus gerentes refletida na habilidade de usá-la para de forma consistente elevar a performance da empresa" [Weill e Ross 2010]. Estas empresas que possuem conhecimento em TI se distinguem das outras por possuírem uma plataforma digitalizada, que consiste em um conjunto integrado de processos de negócios e de tecnologias, aplicativos e dados que suportam tais processos.

Uma empresa com conhecimento em TI não é necessariamente um empresa de alta tecnologia, mas sem exceções estas empresas a utilizam para viabilizar suas principais transações e utilizam os dados de suas transações para comunicar os tomadores de decisão [Weill e Ross 2010].

O conhecimento em TI deve ser aprendido pela organização, seus gerentes, executivos e demais interessados. O aprendizado do conhecimento em TI não é algo trivial, por levar em conta diversos aspectos da organização, muitos deles subjetivos, como a cultura da organização. Dessa forma, o conhecimento em TI vai sendo adquirido conforme a organização vai utilizando-a para alcançar seus objetivos e metas estratégicas.

\subsection{SWOT}

A análise SWOT (SWOT - Strengths, Weaknesses, Opportunities and Threats) é uma técnica há muito tempo conhecida e utilizada pelas organizações e centros de estudos acadêmicos para se visualizar o seu desenvolvimento interno e o posicionamento com relação ao ambiente nos quais estão inseridas.

Elas consistem em elencar pontos fortes, pontos fracos, oportunidades e ameaças. Esta classificação depende de fatores favoráveis ou desfavoráveis, internos ou externos à organização, segundo a figura 3 . 


\begin{tabular}{|c|c|c|}
\cline { 2 - 3 } \multicolumn{1}{c|}{} & Fatores Internos & Fatores Externos \\
\hline Fatores Favoráveis & Pontos Fortes & Oportunidades \\
\hline Fatores Desfavoráveis & Pontos Fracos & Ameaças \\
\hline
\end{tabular}

Figura 3 - Estrutura conceitual da técnica SWOT [Valentin, 2001]

$\mathrm{Na}$ figura pode-se verificar que os pontos fortes e fracos dependem de fatores favoráveis e desfavoráveis internos à organização, entretanto as oportunidades e ameaças dependem de fatores favoráveis ou desfavoráveis externos à organização. No trabalho atual serão utilizados apenas os pontos fortes e fracos, dessa forma serão levados em conta apenas fatores internos à organização. Os resultados posteriormente serão aplicados a uma classificação para melhor desenvolver uma visão geral da TI da organização.

\section{Metodologia}

Para auxiliar os profissionais de TI, gestores e executivos de organizações desenvolveu-se uma metodologia para o desenvolvimento do conhecimento em governança de TI (MDCGTI). Esta metodologia consiste em um meio informatizado para se diagnosticar a situação da organização e identificar os pontos de melhoria com relação a TI das mesmas.

No mercado de TI existem alguns frameworks e pacotes comerciais que realizam tal tarefa, mas as soluções existentes são muito caras e complexas, de modo que, as micro e pequenas empresas ficam incapacitadas de utilizar tais soluções. Dessa forma tem-se o objetivo de atingir também este tipo de empresa, de modo a permitir a todos um desenvolvimento de TI.

Nas sessões a seguir tem-se a explicação da metodologia desenvolvida. A figura 4 descreve o funcionamento e a interação com o usuário da aplicação que suporta a metodologia de aprendizado.

\begin{tabular}{|c|c|c|c|c|}
\hline & Levantamento & Análi & Solução & Resultados \\
\hline 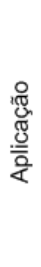 & $\begin{array}{l}\text { Gera dois questionários para o } \\
\text { usuário. Um para extrair } \\
\text { informações sobre o negócio e } \\
\text { seu relacionamento com a TI, } \\
\text { e outra para extrair } \\
\text { informações sobre o estado da } \\
\text { TI. }\end{array}$ & $\begin{array}{l}\text { Com base nas respostas do } \\
\text { usuário o sistema realiza uma } \\
\text { análise SWOT, exibindo os } \\
\text { pontos positivos e negativos } \\
\text { da TI com relação ao negócio. } \\
\text { Tal análise é baseada em um } \\
\text { conjunto de ajustes, pesos e } \\
\text { valores atribuídos as } \\
\text { questões. }\end{array}$ & $\begin{array}{l}\text { Com base nos pontos } \\
\text { positivos e negativos } \\
\text { determinados } \\
\text { anteriormente, o sistema } \\
\text { gera uma lista de possiveis } \\
\text { soluções para se começar a } \\
\text { implantar a Governança de } \\
\text { TI na organização. }\end{array}$ & $\begin{array}{l}\text { O sistema armazena o } \\
\text { resultado obtido pelo usuário, } \\
\text { relacionando-o com a solução } \\
\text { correspondente. De modo a } \\
\text { amadurecer as soluções e } \\
\text { retro alimentar os dados } \\
\text { utilizados pelas análises. }\end{array}$ \\
\hline 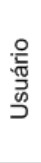 & $\begin{array}{l}\text { Responde aos questionários } \\
\text { gerados pelo sistema de forma } \\
\text { objetiva. }\end{array}$ & & $\begin{array}{l}\text { Usuário pode escolher e } \\
\text { priorizar as soluções } \\
\text { possiveis geradas pelo } \\
\text { sistema. E implantá-las. }\end{array}$ & $\begin{array}{l}\text { O usuário informa os } \\
\text { resultados obtidos com a } \\
\text { solução proposta (positivo ou } \\
\text { negativo, lições aprendidas, } \\
\text { dificuldades) }\end{array}$ \\
\hline
\end{tabular}

Figura 4 - Descrição da função pelas fases da aplicação de suporte a metodologia de aprendizado de conhecimento em governança de $\mathrm{TI}$.

A figura 5 exibe o fluxo de dados realizado pela aplicação que suporta a metodologia de aprendizado de governança de TI. 


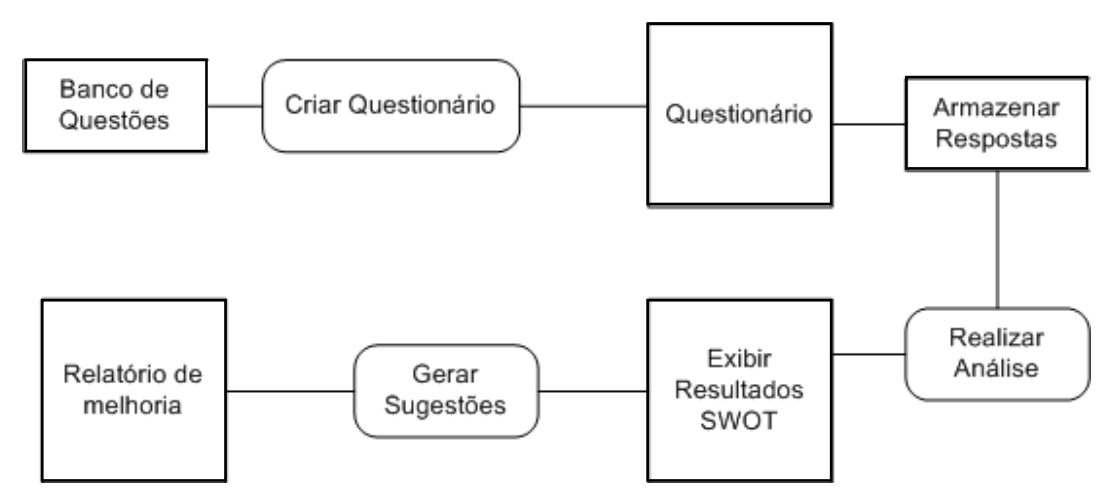

Figura 5 - Processo informatizado utilizado pela aplicação.

\subsection{Questionário}

O questionário tem sido uma importante técnica investigativa. Ele pode ser definido como uma técnica de investigação composta por um número de questões apresentadas por escrito às pessoas, tendo por objetivo extrair informações sobre opiniões, crenças, sentimentos, interesses, expectativas, situações vivenciadas, etc [Gil, 1995].

Como etapa inicial da metodologia tem-se a extração de informações sobre a situação atual e desejada, tecnológica e do negócio da organização em estudo. Para tal atividade, o questionário mostra-se como uma técnica adequada. $\mathrm{O}$ objetivo desta atividade é conseguir obter a situação atual e a ideal da organização, no que diz respeito a TI e consequentemente verificar sua aderência aos negócios da organização, dessa forma tornase possível conhecer o modo como a organização trata a TI.

Dessa maneira, as questões do questionário são classificadas entre questões de negócio e questões de tecnologia, possibilitando assim a criação de um vínculo entre aspectos do negócio e características de TI, esta relação também é ponderada de modo a se extrair o impacto e a severidade que determinadas características de TI geram sobre o negócio, a fim de se definir um melhor alinhamento entre TI e negócio. A tabela 1 traz exemplos de questões, seus relacionamentos e ponderação.

Pode-se notar na tabela que as questões de negócio direcionam as questões de tecnologia de forma a extrair o nível de aderência da TI ao negócio. As questões de tecnologia por sua vez, possuem um peso que retrata a influência de determinado aspecto tecnológico sobre algum objetivo de negócio e além deste peso as respostas das questões de tecnologia são ponderadas de modo a verificar o seu grau de implantação e, consequentemente identificar falhas e pontos fracos em sua operação. Assim, com os resultados dos questionários pode-se analisar e mapear quais características de TI impactam em quais aspectos do negócio e ainda pode-se ter uma noção do nível de implementação e operação de ativos de TI que apoiam o negócio. Ainda para se determinar o nível de implantação e identificar os pontos fracos e falhas de uma característica da TI podem ser necessárias mais do que uma questão de TI.

Espera-se que com o a utilização do questionário e com a continuidade das pesquisas as questões tanto de negócio como de TI aumentem em número, precisão, detalhamento e assertividade. 


\subsection{Análise}

Como segunda atividade da MDCGTI, é realizada uma análise que visa conhecer mais profundamente os aspectos positivos e negativos da TI com relação aos negócios e determinar os pontos em que a TI está agregando valor ou apenas suportando o negócio.

Para a realização da análise utiliza-se uma adaptação da técnica de SWOT (Strenghts, Weaknesses, Opportunities, Threats) - Pontos Fortes, Pontos Fracos, Oportunidades e Ameaças. Aonde são levados em consideração apenas fatores internos da organização (Pontos Fortes e Fracos). Para tal análise são levados em conta os pesos das questões de negócio e de tecnologia de forma que através das relações estabelecidas entre elas é possível identificar os pontos fortes e fracos internos à organização.

As análises destes pontos são fortemente dependentes do negócio da organização, pois uma mesma característica de TI pode ser considerada um ponto forte para um negócio e/ou ponto fraco para outro. Os pontos fortes e fracos também exercem influência uns sobre os outros, visto que podem existir dependências entre eles, como por exemplo: possuir um servidor interno pode ser um ponto forte para o negócio, consequentemente o fato de ter o suporte terceirizado é um ponto fraco, contudo a terceirização tem sido uma opção muito eficiente em outros casos. E a partir dos pontos determinados é gerada uma matriz SW, como na figura 6.

$\mathrm{Na}$ figura 6 pode-se ver um exemplo de matriz SW, pontos fortes e fracos com relação ao negócio, no eixo horizontal estão localizadas as ferramentas, técnicas práticas, processos, entre outros ativos de TI, realizados ou necessários para organização e no eixo vertical existe uma escala que quantifica a influência deste ativo no negócio, de acordo com as informações do questionário, obtidas através dos pesos atribuídos à cada resposta. Ainda se tem uma descrição de cada característica de TI contida no eixo horizontal, que informa se ela está sendo executada, se ela é necessária, se tem erros na execução, entre outros dados relevantes. Dessa forma, consegue-se ter uma visão geral de como a TI está ajudando o negócio e a organização. Assim é possível gerar um diagnóstico e identificar onde a organização necessita aplicar ou cortar investimentos, o que deve ser priorizado, qual melhoria irá agregar mais valor ao negócio, dentre outros.

Tabela 1 - Exemplo do questionário

\begin{tabular}{|l|l|l|}
\hline$\underline{\text { ID }}$ & Questão & $\underline{\text { Tipo }}$ \\
\hline N001 & $\begin{array}{l}\text { Qual o grau de dependência da tecnologia da } \\
\text { organização? }\end{array}$ & Negócio \\
\hline A & $\begin{array}{l}\text { Todos os processos da organização dependem de tecnologia, ou seja, quando a TI para } \\
\text { de funcionar a organização fica impossibilitada de funcionar. }\end{array}$ \\
\hline B & $\begin{array}{l}\text { A organização é fortemente dependente da Tecnologia, os ativos tecnológicos } \\
\text { influenciam no funcionamento de mais de 80\% dos processos organizacionais. }\end{array}$ \\
\hline C & $\begin{array}{l}\text { A organização é fracamente dependente da Tecnologia, os ativos tecnológicos } \\
\text { influenciam no funcionamento de 20\% a 80\% dos processos organizacionais. }\end{array}$ \\
\hline D & $\begin{array}{l}\text { A organização continua sua operação mesmo com a paralização dos ativos tecnológicos } \\
\text { da organização. }\end{array}$ & Peso 5 \\
\hline TI001 & $\begin{array}{l}\text { Existe uma infraestrutura tecnológica adequada para a } \\
\text { recuperação de falhas? }\end{array}$ & \multicolumn{2}{|c|}{ Tecnologia } \\
\hline A & $\begin{array}{l}\text { A infraestrutura de TI da organização foi projetada para se recuperar de falhas } \\
\text { e foi atestado que caso ocorra uma falha a organização não para sua operação. }\end{array}$ & . \\
\hline
\end{tabular}




\begin{tabular}{|c|c|c|}
\hline $\mathrm{B}$ & $\begin{array}{l}\text { A infraestrutura de TI da organização foi projetada para se recuperar de } \\
\text { falhas, mas nunca foi testada. }\end{array}$ & 1 \\
\hline $\mathrm{C}$ & $\begin{array}{l}\text { A infraestrutura de TI da organização não foi projetada para se recuperar de } \\
\text { falhas, foi evoluindo conforme a necessidade, mas opera bem. }\end{array}$ & -1 \\
\hline $\mathrm{D}$ & $\begin{array}{l}\text { A infraestrutura de TI da organização não foi projetada para se recuperar de } \\
\text { falhas, foi evoluindo conforme a necessidade, e não possuí uma boa operação. }\end{array}$ & -3 \\
\hline TI002 & $\begin{array}{l}\text { Existe uma política de backup estabelecida para a } \\
\text { organização? }\end{array}$ & Peso 2 \\
\hline A & $\begin{array}{l}\text { Os backups da organização são realizados periodicamente testados e } \\
\text { armazenados em local diferente. A política de backup é revisada } \\
\text { periodicamente e são revistos os conteúdos e periodicidade. }\end{array}$ & 3 \\
\hline $\mathrm{B}$ & $\begin{array}{l}\text { Os backup são realizados periodicamente, mas a política não é revisada } \\
\text { periodicamente; e/ou os backups não são armazenados em local diferente; } \\
\text { e/ou os backups não são testados após gravados. }\end{array}$ & $\begin{array}{l}-2,-1 \\
1 *\end{array}$ \\
\hline $\mathrm{C}$ & Os backups são realizados sem nenhum critério & -2 \\
\hline $\mathrm{D}$ & Não são realizados backups & -3 \\
\hline TI003 & $\begin{array}{l}\text { Existe um ou mais profissionais capacitados } \\
\text { responsáveis pela TI da organização? }\end{array}$ & Peso 5 \\
\hline A & $\begin{array}{l}\text { Existem um ou mais de profissionais capacitados em todas as tecnologias } \\
\text { utilizadas pela organização. }\end{array}$ & 3 \\
\hline B & $\begin{array}{l}\text { Existem um ou mais de profissionais não capacitados nas tecnologias } \\
\text { utilizadas pela organização. }\end{array}$ & -1 \\
\hline $\mathrm{C}$ & $\begin{array}{l}\text { A responsabilidade pela TI é terceirizada, e existe um profissional terceiro } \\
\text { capacitado } 24 \times 7 \text { dentro da organização para resolver problemas. }\end{array}$ & 3 \\
\hline $\mathrm{D}$ & $\begin{array}{l}\text { A responsabilidade pela TI é terceirizada, e é acionada quando ocorre alguma } \\
\text { falha. }\end{array}$ & -3 \\
\hline
\end{tabular}

*neste caso existem 3 opções: caso $3 \mathrm{~V}=$ Peso -2 , caso $2 \mathrm{~V}$ peso $=-1$ e caso $1 \mathrm{~V}$ peso $=1$.

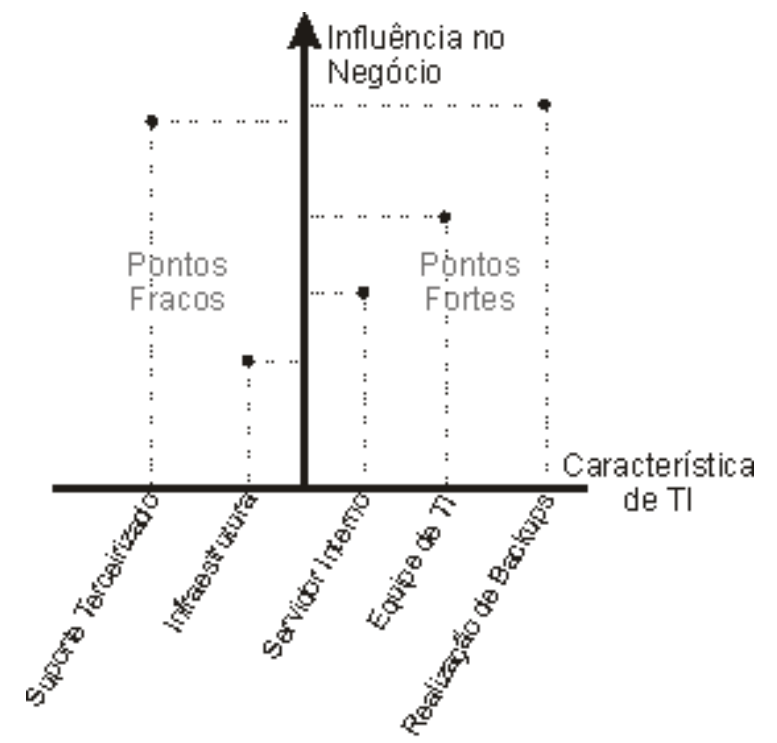

Figura 6 - Matriz SW - Característica de TI x Influência no Negócio

Com esta análise é possível mostrar aos gestores os impactos dos ativos e características de TI sobre o negócio da organização. E a partir dela sugerem-se melhorias e soluções que podem ser realizadas para melhorar a TI da organização. As melhorias e soluções ficam armazenadas em um banco de dados que armazena o resultado da análise, o 
que foi realizado para melhorar a TI da organização e o resultado obtido na organização. Tudo isso pode ser feito de modo a preservar a identidade da organização, mas é importante que se tenha o resultado da análise para relacioná-lo com as soluções aplicadas e os resultados obtidos. Dessa forma vai-se construindo um Banco de dados de conhecimento em Governança de TI.

\subsection{Banco de Dados de Conhecimento em Governança de TI (BDCGTI)}

O BDCGTI consiste em um repositório de soluções de TI que contém informações tais como: descrição das soluções, palavras chave, referências bibliográficas, técnicos ou equipe técnica com experiência na solução, ferramentas adequadas entre outros. As soluções são relacionadas com a análise realizada anteriormente e com os resultados obtidos com suas aplicações anteriores.

As soluções contidas no BDCGTI são resultados de pesquisas realizadas no projeto GERTI da Universidade Estadual de Londrina, que visam descobrir soluções aplicáveis à micro e pequenas empresas que sejam capazes de agregar valor ao negócio com baixo custo, eficiência e eficácia. Dentre as soluções encontram-se ferramentas livres, sugestões de processos e sugestões de serviços (prestados pelo próprio projeto), ferramentas proprietárias também são sugeridas, mas como uma opção à organização.

O BDCGTI está em constante evolução e novas soluções são adicionadas a ele com o passar do tempo. Dessa forma, as empresas que utilizam esta metodologia proposta alimentam o BDCGTI, e em contra partida adquirem mais conhecimento em TI.

É importante ressaltar que nenhuma solução encontra-se pronta no BDCGTI, uma vez que ele é um banco de dados de conhecimento, e que, a partir da análise das informações por ele armazenadas, pode-se obter indícios de qual solução já conhecida e/ou existente pode ser adequada à organização, porém esta solução precisa ser trabalhada e customizada de modo a atender as especificidades de cada organização. Por exemplo, uma solução de backup já é conhecida, conhece-se uma ferramenta e seu funcionamento, e sabe-se como criar uma política de backup, no caso de uma organização optar por implantar uma solução de backup, a política de backup será definida (diferente para cada organização) e a ferramenta será customizada de forma a atender a política definida e se adequar ao ambiente da organização.

Dessa forma, é possível armazenar as informações do que gerou a necessidade de melhoria na organização, o que foi utilizado para realizar esta melhoria, como foi utilizado e quais resultados foram alcançados com a aplicação da solução.

\subsection{Soluções}

Todas as soluções contidas no BDCTGI foram previamente avaliadas em pesquisas do projeto ou em organizações que as utilizaram anteriormente. Espera-se que, com o passar do tempo, as soluções sejam aprimoradas e novas soluções surjam, de modo a completar o repositório.

Algumas soluções podem ser complementares como, por exemplo, a instalação de um servidor interno e a capacitação de uma equipe de TI, ou até mesmo dependentes. As soluções não exercem influência sobre a análise realizada anteriormente na metodologia, mas influencia no modo de como as melhorias serão realizadas na organização. 


\section{Resultados}

Como resultado deste trabalho tem-se a metodologia para desenvolvimento do conhecimento em governança de TI, que torna possível que micro e pequenas empresas a desenvolvam de modo planejado e controlado, e ainda adquiriram conhecimento de TI durante seu crescimento. A aplicação da metodologia nas organizações alimenta o repositório de dados da metodologia, o que a evolui e robustece as soluções, além de gerar material para futuras pesquisas. Tal resultado favorece a integração entre a academia e o mercado corporativo.

A metodologia se mostrou interessante, de fácil uso e entendimento, com isso espera-se que mais empresas e organizações a utilizem para adquirirem conhecimentos em governança de TI, fazendo assim com que a metodologia amadureça e possa consequentemente agregar mais valor às organizações que dela fizerem uso.

\section{Conclusão}

A metodologia apresentada neste artigo mostrou-se de fácil uso e entendimento por parte de seus usuários, no entanto, a governança de TI é um assunto muito amplo e é conveniente que a metodologia seja realimentada constantemente por lições aprendidas no decorrer de sua aplicação nas organizações. Dessa forma, conforme a metodologia for sendo aplicada, suas soluções serão incrementadas e aprimoradas e também seu mecanismo de avaliação poderá ser revisado, amadurecido e adaptado conforme as necessidades.

Com este mecanismo de apoio às pequenas e médias organizações será possível tornar acessíveis a elas soluções que até então eram restritas à grandes empresas, devido a altos custos e complexidade. Além disso, a utilização da metodologia contribuirá para a comunidade científica com material de pesquisa e dados para estudos de novos caminhos para obter uma melhor governança de TI.

\section{Referências}

Albertin, A. L. (2004), “Administração de Informática: funções e fatores críticos de sucesso", Atlas, Brasil.

Albertin, A. L. (2008), "Albertin, R. M. de M., Benefícios do uso da tecnologia de informação para o desempenho empresarial", Revista de Administração Pública, Mar/Abr 2008, FGV, Rio de Janeiro, Brasil, p. 275 - 302.

Briganó, U. G. e Barros, R. M. (2010), “A Implantação de um Service Desk: Um Estudo de Caso Aplicando Conceitos do ITIL e do PMBOK", XXXVIII Congresso Brasileiro de Educação em Engenharia - COBENGE 2010, Brasil.

Fagundes, E. M. (2009). "Cobit - Um kit de ferramentas para gestão de TI". Disponível em: http://www.efagundes.com/Artigos/COBIT.htm. Acesso em: 11/02/11.

Gama, F. A. e Martinello, M. (2006), “Governança de Tecnologia da Informação: Um estudo em empresas brasileiras", $4^{\circ}$ Simpósio FUCAPE de produção científica, Brasil.

GIL, A.C. Métodos e técnicas de pesquisa social. 4ªed. São Paulo, Atlas, 1995.

ITGI - Information Technology Institute - www.itgi.org - acessado em Janeiro de 2011.

ITSMF (2007), "ITIL V3 - Service Strategy". (2007), "ITIL V3 - Service Design". 
(2007), “ITIL V3 - Service Transaction”.

(2007), "ITIL V3 - Service Operation".

(2007), "ITIL V3 - Continual Service Improvement”.

(2007), "ITIL V3 - Introduction to Official Service Life Cicle".

Lunardi, G. L., Becker, J. L., Maçada, A. C. G. (2010), "Impacto da Adoção de Mecanismos de Governança de Tecnologia da Informação (TI) no desempenho da Gestão da TI: uma análise baseada na percepção dos executivos", Revista de Ciências da Administração, v. 12, n. 28, p. 11-39, set/dez 2010.

Magalhães, I. L. e Pinheiro, W. B. (2007), “Gerenciamento de Serviços de TI na prática: Uma abordagem com base na ITIL ${ }^{\circledR}$, , Novatec, Brasil.

Project Manage Institute (2010), “A guide to Project Managemant Body of Knowledge PMBOK® guide”, Pennsylvania, USA.

Silveira, A. D. M. (2010), "Governança corporativa no Brasil e no Mundo: Teoria e Prática", Campus, Brasil

Porter, M. E (1989), "Vantagem Competitiva, criando e sustentando um desempenho superior", Campus, Brasil

(1980), "Estratégia Competitiva, técnicas para análise de indústrias e da concorrência", Campus, Brasil

Valentin, E, K (2001), "SWOT analysis from a resource-based view", Journal of Marketing Theory and Practice, Estados Unidos

Weill, P. e Ross, J. W. (2009), "Conhecimento em TI: o que os executivos precisam saber para conduzirem com sucesso TI em suas empresas", Harvard Business Press, M.Books, Brasil.

(2006), "Governança de TI, tecnologia da informação", M.Books, Brasil. 